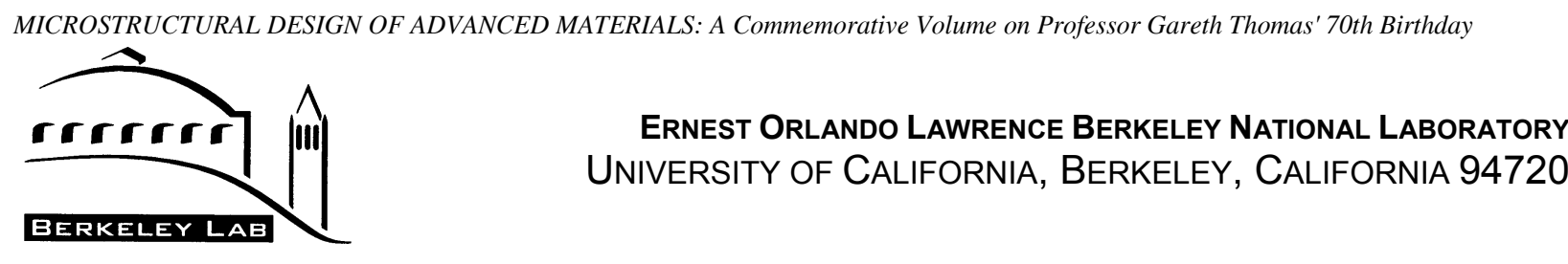

MATERIALS SCIENCES DIVISION

LBNL-52628

MICROSTRUCTURE AND PROPERTIES OF IN SITU TOUGHENED SILICON CARBIDE

\author{
LUTGARD C. DE JONGHE ${ }^{1,2}$, R. O. RITCHIE ${ }^{1,2}$, XIAO FENG ZHANG $^{1}$ \\ ${ }^{1}$ Materials Sciences Division, Lawrence Berkeley National Laboratory, University of California, \\ Berkeley, CA 94720, USA \\ ${ }^{2}$ Department of Materials Science and Engineering, University of California, Berkeley, CA 94720 , \\ USA
}

May 8, 2003

Submitted to

MICROSTRUCTURAL DESIGN OF ADVANCED MATERIALS: A Commemorative Volume on Professor Gareth Thomas' 70th Birthday

Work supported by the Director, Office of Energy Research, Office of Basic Energy Sciences, Materials Sciences Division of the U.S. Department of Energy under Contract No. DE-AC0376SF0098. 


\title{
Microstructure and Properties of In Situ Toughened Silicon Carbide
}

\author{
Lutgard C. De Jonghe $^{1,2}$, R. O. Ritchie ${ }^{1,2}$ and Xiao Feng Zhang ${ }^{1}$ \\ ${ }^{1}$ Materials Sciences Division, Lawrence Berkeley National Laboratory, \\ University of California, Berkeley, CA 94720, USA \\ ${ }^{2}$ Department of Materials Science and Engineering, \\ University of California, Berkeley, CA 94720, USA
}

\begin{abstract}
A silicon carbide with a fracture toughness as high as $9.1 \mathrm{MPa} \cdot \mathrm{m}^{1 / 2}$ has been developed by hot pressing $\beta$-SiC powder with aluminum, boron, and carbon additions (ABC-SiC). Central in this material development has been systematic transmission electron microscopy (TEM) and mechanical characterizations. In particular, atomic-resolution electron microscopy and nanoprobe composition quantification were combined in analyzing grain boundary structure and nanoscale structural features. Elongated $\mathrm{SiC}$ grains with $1 \mathrm{~nm}$-wide amorphous intergranular films were believed to be responsible for the in situ toughening of this material, specifically by mechanisms of crack deflection and grain bridging. Two methods were found to be effective in modifying microstructure and optimizing mechanical performance. First, prescribed postannealing treatments at temperatures between 1100 and $1500^{\circ} \mathrm{C}$ were found to cause full crystallization of the amorphous intergranular films and to introduce uniformly dispersed nanoprecipitates within SiC matrix grains; in addition, lattice diffusion of aluminum at elevated temperatures was seen to alter grain boundary composition. Second, adjusting the nominal content of sintering additives was also observed to change the grain morphology, the grain boundary structure, and the phase composition of the $\mathrm{ABC}-\mathrm{SiC}$. In this regard, the roles of individual additives in developing microstructure were identified; this was demonstrated to be critical in optimizing the mechanical properties, including fracture toughness and fatigue resistance at ambient and elevated temperatures, flexural strength, wear resistance, and creep resistance.
\end{abstract}

\section{INTRODUCTION}

Silicon carbide ( $\mathrm{SiC}$ ) offers many intrinsic advantages as a structural ceramic, including a high melting temperature, low density, high elastic modulus and hardness, excellent wear resistance, and low creep rates at elevated temperatures. This remarkable combination of features make $\mathrm{SiC}$ one of the most promising advanced structural ceramic materials for a variety of advanced engineering technologies. An imperative in these structural applications is high fracture toughness, which for commercially available $\mathrm{SiC}$ is typically on the order of $3 \mathrm{MPa} \cdot \mathrm{m}^{1 / 2}$, well below that of grain-elongated $\mathrm{Si}_{3} \mathrm{~N}_{4}$ and yttria-stabilized $\mathrm{ZrO}_{2}$, for example. This low toughness clearly limits its utility. 
The toughening of ceramic materials can best be induced by crack bridging mechanisms (i.e., extrinsic toughening by crack-tip shielding), which can result from crack paths bridged by unbroken reinforcement fibers in composite ceramics (ex situ toughening) [1-3], or by selfreinforcement from elongated grains in monolithic ceramics (in situ toughening) [4]. The latter approach was exploited in the present work by hot pressing $\mathrm{SiC}$ with $\mathrm{Al}, \mathrm{B}$ and $\mathrm{C}$ additives (ABC-SiC [5]). Two strategies, specifically post-annealing heat treatments and changes in the additive content, were used to optimize the microstructure.

In this paper, we review the microstructure and mechanical properties of in situ toughened SiC. In particular, atomic-resolution TEM in conjunction with nanoprobe chemical analyses were employed to determine the structure and chemistry of the grain boundaries. Such atomic-scale characterization was correlated with materials processing and mechanical testing with the objective of optimizing the structural performance of ABC-SiC.

It is perhaps fitting that this work is presented in a symposium dedicated to the career of Professor Gareth Thomas, who was a pioneer in the development of materials through the use of transmission electron microscopy and intelligent microstructure design - this paper is dedicated to him in recognition of his leading contributions to this field of materials science [e.g., [6,7]].

\section{EXPERIMENTAL PROCEDURES}

Submicron $\beta$-SiC powder was mixed with $3 \mathrm{wt} \%$ aluminum metal powder, $0.6 \mathrm{wt} \%$ boron, and 2 $\mathrm{wt} \%$ carbon sintering. The slurry was stir dried, sieved, and uniaxially pressed at $35 \mathrm{MPa}$. The green bodies were hot pressed at $50 \mathrm{MPa}$ at $1900^{\circ} \mathrm{C}$ for $1 \mathrm{hr}$ in an Ar atmosphere. The final product, which was produced as $99 \%$ dense $\left(3.18 \mathrm{~g} / \mathrm{cm}^{3}\right), 4 \mathrm{~mm}$ thick and $38 \mathrm{~mm}$ diameter disks of polycrystalline $\mathrm{SiC}$, was compromise of predominantly $4 \mathrm{H}$ and $6 \mathrm{H} \alpha$-SiC phases, with a minor fraction of 3C $\beta$-SiC. Some as-hot-pressed $\mathrm{ABC}-\mathrm{SiC}$ samples were further annealed in a tungsten mesh furnace under flowing $\mathrm{Ar}$, at temperatures between 1000 and $1500^{\circ} \mathrm{C}$, for times typically ranging from 72 to $168 \mathrm{hr}$. Structural and mechanical characterizations were performed for both as-hot-pressed and annealed samples.

Structural and chemical analyses were carried out in a $200 \mathrm{kV}$ Philips CM200 transmission electron microscope equipped with a windowless detector and corresponding X-ray energydispersive spectroscopy (EDS) system. A spatial-difference methodology was developed to determine the concentration of the impurities in the $\mathrm{SiC}$ grain boundaries using a nanoprobe with a diameter varied between 3 and $20 \mathrm{~nm}[8,9]$.

Indentation hardness, four-point bending strength, creep resistance, abrasive wear properties, Rcurve fracture toughness, and cyclic fatigue-crack growth behavior at ambient and elevated temperatures were all evaluated for $\mathrm{ABC}-\mathrm{SiC}$. Experimental procedures for each of these mechanical property assessments are described in detail in the respective references quoted in this paper. 


\section{RESULTS}

\section{General Aspects}

Some typical mechanical properties for as-processed ABC-SiC are summarized in Table 1. Of particular note is the fracture toughness, which has been measured to be as high as 7 to 9 $\mathrm{MPa} . \mathrm{m}^{1 / 2}$; this is the highest $K_{\mathrm{Ic}}$ value recorded for $\mathrm{SiC}$ to date.

TABLE 1

ROOM TEMPERATURE MECHANICAL PROPERTIES OF AS-PROCESSED ABC-SiC

\begin{tabular}{|l|c|}
\hline \multicolumn{1}{|c|}{ Sample } & ABC-SiC \\
\hline 4-Point Bending Strength $(\mathrm{MPa})$ & $691 \pm 12$ \\
\hline Hardness* $(\mathrm{GPa})$ & $561 \pm 13$ \\
\hline Fracture Toughness $\left(\mathrm{MPa} \cdot \mathrm{m}^{1 / 2}\right)$ & $6.8-9.1( \pm 0.4)$ \\
\hline
\end{tabular}

$*$ Vickers indentation, Load $=10 \mathrm{~kg} . E=430 \mathrm{GPa}$ for the calculation.

Using X-ray diffraction, 70 vol.\% of the hot-pressed structure was identified as hexagonal $4 \mathrm{H}$ $\mathrm{SiC}$ and the remaining $30 \%$ as cubic $3 \mathrm{C}$-SiC. TEM studies revealed that the $3 \mathrm{C}$-to- $4 \mathrm{H}$ phase transformation, which is presumed to have occurred during hot pressing, promoted anisotropic grain growth [10], resulting in high area density of plate-like, elongated SiC grains (Figure 1a); the length and width of these grains ranged from 3 to $11 \mu \mathrm{m}$ and 1 to $3 \mu \mathrm{m}$, respectively, with an aspect ratio for $90 \%$ of them between 2 and 5 . Interlocking between the elongated $\mathrm{SiC}$ grains was often observed, as shown in Figure 1b. Equiaxed 3C-SiC grains with a submicron size were also found in $\mathrm{ABC}-\mathrm{SiC}$. It is believed that the unusually high toughness of $\mathrm{ABC}-\mathrm{SiC}$ results from a combination of crack deflection and principally frictional and elastic bridging by the elongated $\mathrm{SiC}$ grains in the wake of the crack tip [5,11]. To optimize this toughening mechanism, an understanding of the grain boundary properties and structure is crucial; consequently, extensive TEM studies were focused on this feature of the microstructure.
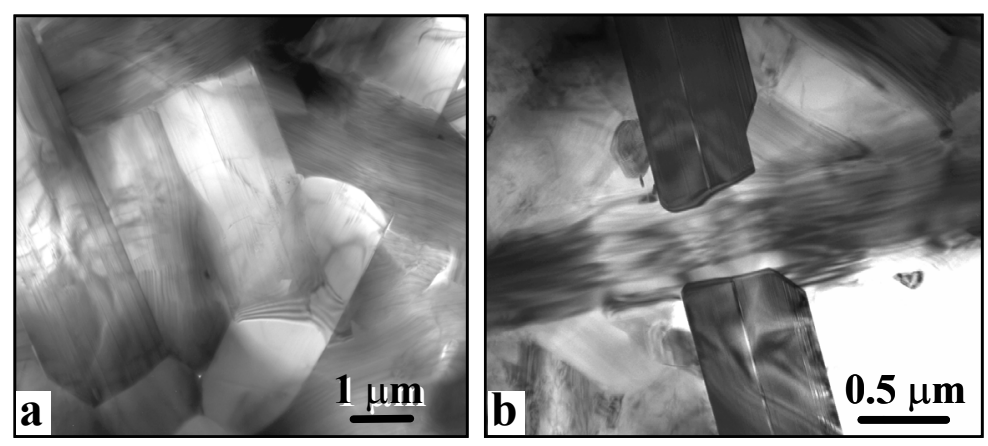

Figure 1: (a) Bright-field TEM images showing elongated SiC grains in ABC-SiC.

(b) Two elongated grains are interlocked. 
Figure 2a shows a high-resolution TEM image of a typical grain boundary area in as-pressed ABC-SiC. An amorphous intergranular film is seen between two adjacent SiC grains, about 1 $\mathrm{nm}$ in width. Using high-resolution electron microscopy, the statistical width of these films was determined; results are shown in Figure 2b. Specifically, the amorphous grain boundary films range in width from about 0.75 to $2.75 \mathrm{~nm}$, with a mean of $\sim 1 \mathrm{~nm}$. This width is consistent with the values found in other ceramic materials $[12,13]$, and with theoretical explanations developed by Clarke [14]. In some particularly wide films (e.g. $\sim 2.75 \mathrm{~nm}$ ), nanoscale crystallites were recognizable, indicating local ordering in the glassy films. Earlier work on SiC sintered with boron and carbon showed a solid-phase sintering procedure with no grain boundary films being formed $[15,16]$. The formation of the current films was due to liquid-phase sintering promoted by the $\mathrm{Al}$ additives. The liquid phase allowed for densification of the $\mathrm{SiC}$ at temperatures roughly $200^{\circ} \mathrm{C}$ lower than $\mathrm{Al}$-free compositions, i.e., at $\sim 1900^{\circ} \mathrm{C}$ instead of $\sim 2100^{\circ} \mathrm{C}$. The amorphous intergranular films provide the preferred crack path, which is an essential element for the development of crack bridging and hence toughening in ABC-SiC.
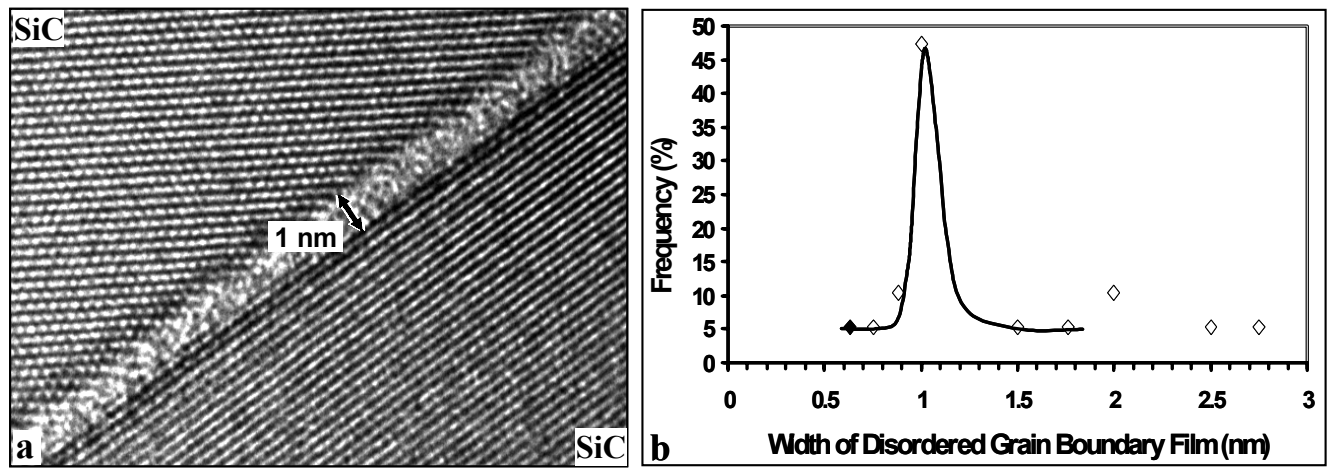

Figure 2: (a) High-resolution electron micrograph showing a typical intergranular film between two $\mathrm{SiC}$ matrix grains. An amorphous structure is observed with a width of about $1 \mathrm{~nm}$.

(b) Distribution of amorphous grain boundary widths determined by high-resolution electron microscopy. The grain boundary width ranges from $0.75 \mathrm{~nm}$ to $2.75 \mathrm{~nm}$, with a mean of about 1 nm.

Nanoprobe EDS analyses revealed that the grain boundary films contained substantial Al, O, Si, and $\mathrm{C}$. The oxygen came mainly from the $\mathrm{SiO}_{2}$ surface oxidation of the $\mathrm{SiC}$ starting powder, and is one of the features responsible for difference in the behavior of different starting powders. Boron was below the detectability limit at the grain boundaries and in the interior of the $\mathrm{SiC}$ grains. In fact, boron was largely involved in forming $\mathrm{Al}_{8} \mathrm{~B}_{4} \mathrm{C}_{7}$ secondary phases. Other secondary phases identified in $\mathrm{ABC}-\mathrm{SiC}$ include $\mathrm{Al}_{2} \mathrm{OC}$-SiC, mullite, $\mathrm{Al}_{2} \mathrm{O}_{3}, \mathrm{Al}_{4} \mathrm{C}_{3}, \mathrm{Al}_{4} \mathrm{O}_{4} \mathrm{C}$, and Al-O-C-B crystalline phases. These secondary phases were submicron in dimension and were present as triple-junction particles [8,17]. Al in solution in the $\mathrm{SiC}$ matrix grains was also detected. Similar to $\mathrm{SiC}$ studied here, $\mathrm{Al}$ and $\mathrm{O}$ concentrations in grain boundaries and their effects on $\mathrm{Si}_{3} \mathrm{~N}_{4}$ phase transformation were reported by Goto and Thomas [18]. 


\section{Effects of Post-annealing}

The most significant phenomenon that we observed in the efforts of modifying microstructure of $\mathrm{ABC}-\mathrm{SiC}$ was crystallization of amorphous intergranular films in post-annealing. While no significant change in the overall, large-scale microstructure was recognized, annealing at $1000^{\circ} \mathrm{C}$ for only 5-30 hours was sufficient to transform about half number of the amorphous grain boundary films into more ordered structures. Apparently, $1000^{\circ} \mathrm{C}$ was about the threshold temperature for activation of grain boundary diffusion. Annealing at higher temperatures for prolonged hours fully crystallized the intergranular films [8]. For example, whereas about 90\% of the grain boundaries were amorphous in as-hot-pressed samples, $86 \%$ of the intergranular films in the annealed material were found to be crystalline. Figure 3a shows a high-resolution TEM image of a grain boundary film crystallized after annealing at $1200^{\circ} \mathrm{C}$ for $500 \mathrm{hrs}$. In this image, the crystallized grain boundary film is not readily distinguishable because the grain boundary phase was strictly epitaxial with the $6 \mathrm{H}-\mathrm{SiC}$ grain on the left-hand side. However, corresponding EDS detected substantial Al-O-Si-C segregations between the two SiC grains, confirming the existence of the boundary phase. An enlarged image from the framed area is shown in Figure $3 \mathrm{~b}$ for closer inspection. The two adjacent $\mathrm{SiC}$ grains in this image show very different orientations. Due to a large deviation from the $[11 \overline{2} 0]$ type zone-axes, only (0004) lattice fringes, with the lattice spacing of $0.25 \mathrm{~nm}$, could be resolved for the $4 \mathrm{H}-\mathrm{SiC}$ grain on the upper-right side, while a two-dimensional [11 $\overline{2} 0$ ] zone-axis lattice can be recognized in the $6 \mathrm{H}-$ $\mathrm{SiC}$ grain on the other side of the grain boundary. Under the imaging conditions for Figure 3 , the black dots in the image correspond to cationic columns along the incident electron beam direction. Some black dots in the $6 \mathrm{H}-\mathrm{SiC}$ grain were marked with black circles. The zigzag stacking of the dots correspond to the ...ABCACBABCACB... hexagonal structure of the $6 \mathrm{H}-$ $\mathrm{SiC}$. The closest layer spacing along the c-direction is $0.25 \mathrm{~nm}$.
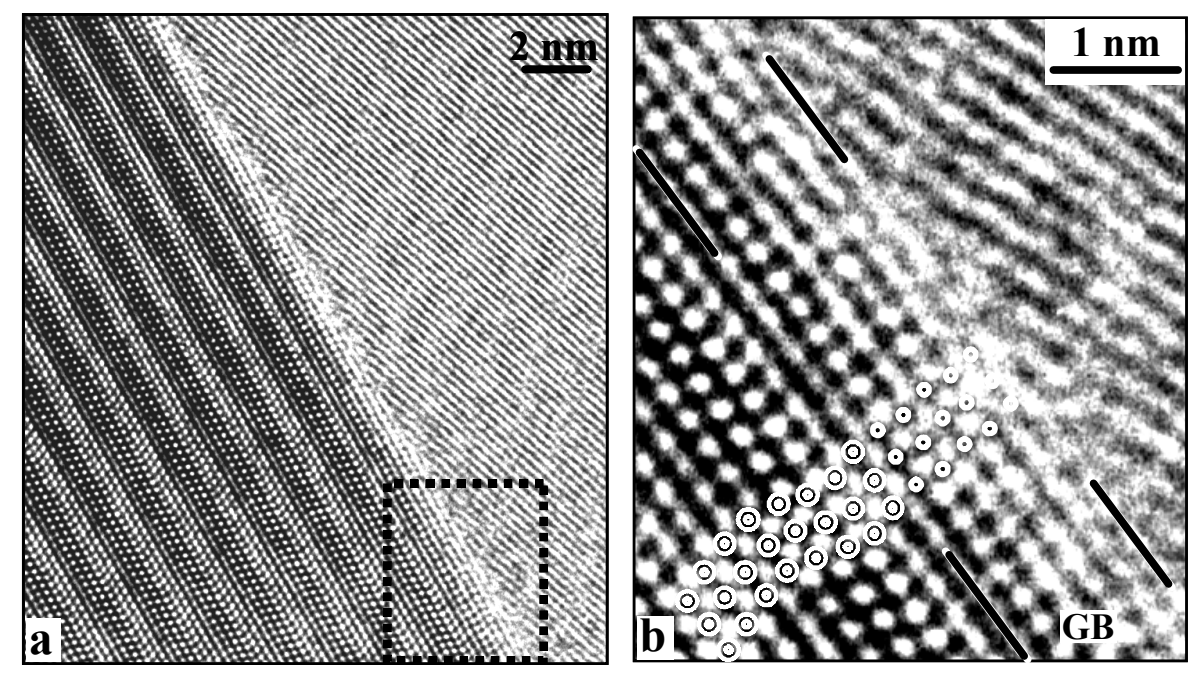

Figure 3: (a) High-resolution electron microscopy image for a grain boundary area in $\mathrm{ABC}-\mathrm{SiC}$ annealed at $1200^{\circ} \mathrm{C}$ for $500 \mathrm{hrs}$. Amorphous intergranular film is crystallized. (b) Enlarged image from the framed area in (a). Atomic stacking in $6 \mathrm{H}-\mathrm{SiC}$ grain on the bottom-left side is marked by black circles. $2 \mathrm{H}$-wurtzite atomic stacking in grain boundary film (GB) are marked by white circles. Note the epitaxial orientation relationships between the grain boundary film and the $6 \mathrm{H}-\mathrm{SiC}$ matrix grain. 
The grain boundary layer outlined in Figure $3 \mathrm{~b}$ can be distinguished by the abrupt change in the atomic arrangement. Some lattice points in the boundary region are marked with white circles. The projection distance between adjacent lattice dots in the grain boundary layers is very close to that in the neighboring $6 \mathrm{H}-\mathrm{SiC}$ grain, and the characteristic zigzag lattice arrangement is also apparent in the boundary layer. These observations would suggest a grain boundary film structure similar to $6 \mathrm{H}-\mathrm{SiC}$. However, instead of the ...ABCACBABCACB... periodic stacking for every six layers in the 6H-type structure, the stacking period in the grain boundary phase contains only two layers in one period, resulting in ...ABABAB... stacking with an $0.5 \mathrm{~nm}$ repeat length, within a grain boundary width of about $1.25 \mathrm{~nm}$. In conjunction with the quantitative analysis of the grain boundary composition and computer image simulations, we concluded that one of the intergranular crystalline phases was aluminosilicate with a $\mathrm{Al}_{2} \mathrm{OC}-\mathrm{SiC}$ solid solution composition and a $2 \mathrm{H}$-wurtzite structure (hexagonal unit cell, $a=3.1 \AA, c=5.0 \AA$ ) $[8,19]$. The crystallized structure usually has an epitaxial structural relationship with $\mathrm{SiC}$ matrix grains when the (0001) habit plane is available. As shown in Figure 3, the typical grain boundary width after crystallization remains about $1 \mathrm{~nm}$.

To further study the crystallization process in intergranular films at elevated temperatures, an ABC-SiC sample was heated in situ in a $300 \mathrm{kV}$ JEOL 3010 transmission electron microscope equipped with a hot stage. Figure 4 shows high-resolution images for the same intergranular film before and after in situ heating, respectively. The amorphous film prior to heating crystallized discretely after $25 \mathrm{hrs}$ at $1200^{\circ} \mathrm{C}$, as indicated by arrowheads in Figure $4 \mathrm{~b}$. The crystallization tended to proceed epitaxially on the (0001) plane of the adjacent $6 \mathrm{H}-\mathrm{SiC}$ matrix grain, with a $2 \mathrm{H}$-wurtzite structure similar to that observed in ex situ annealed $\mathrm{SiC}$ samples. No discernable features could be identified as potential preferential sites for nucleation at the $\mathrm{SiC} /$ film interface. Presumably, local compositional fluctuations in the intergranular films serve as nucleation sites.

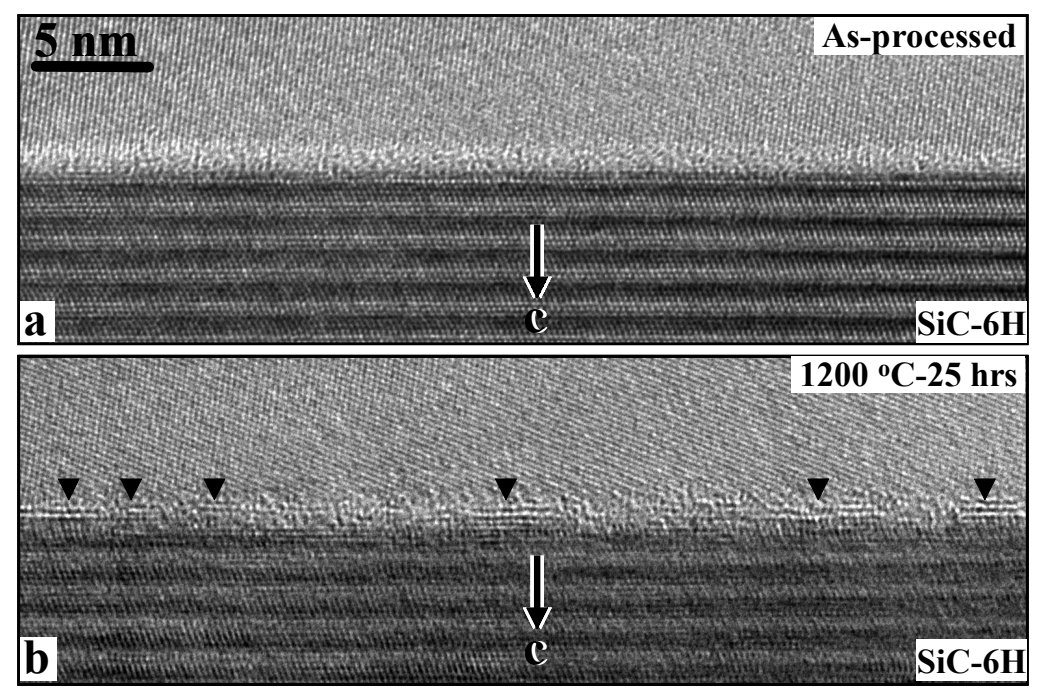

Figure 4: (a) High-resolution image of an amorphous intergranular film in as-hot-pressed ABCSiC. (b) The same film as in (a) but after in situ heating in a transmission electron microscope at $1200^{\circ} \mathrm{C}$ for $25 \mathrm{hrs}$. Arrowheads indicate the discrete, crystallized boundary segments. 
Another significant consequence of the thermal treatment was coherent nano-precipitation within $\mathrm{SiC}$ matrix grains, as seen in Figure 5a. Although Figure 5a was taken from a sample annealed at $1400^{\circ} \mathrm{C}$, the plate-like nanoprecipitates first formed at $1300^{\circ} \mathrm{C}$. The precipitates were uniform in size and shape, and dispersed within the SiC matrix grains. The projected dimension of the precipitates after $1300^{\circ} \mathrm{C}$ annealing is $\sim 4 \times 1 \mathrm{~nm}^{2}$ with a volumetric number density of $5 \times 10^{22} / \mathrm{m}^{3}$. The precipitates coarsened with annealing temperature, accompanied by decrease in the number density. Detailed high-resolution electron microscopy characterization and nanoprobe EDS analysis determined an $\mathrm{Al}_{4} \mathrm{C}_{3}$-based structure and composition for the nanoprecipitates [20]. A comparison between $6 \mathrm{H}-\mathrm{SiC}$ and $\mathrm{Al}_{4} \mathrm{C}_{3}$ structures projected along the [0001] direction is shown in Figure 5b. The similarity between the two structures caused coherent precipitation with the (0001) habit planes. The formation and coarsening of the precipitates at 1300 to $1600^{\circ} \mathrm{C}$ was a consequence of lattice-diffusion-controlled classic nucleation and growth [20]. The diffusion of Al-rich species through SiC lattice starting at $1300^{\circ} \mathrm{C}$ resulted in $\mathrm{Al}$-enrichment in grain boundary films, as revealed by EDS.

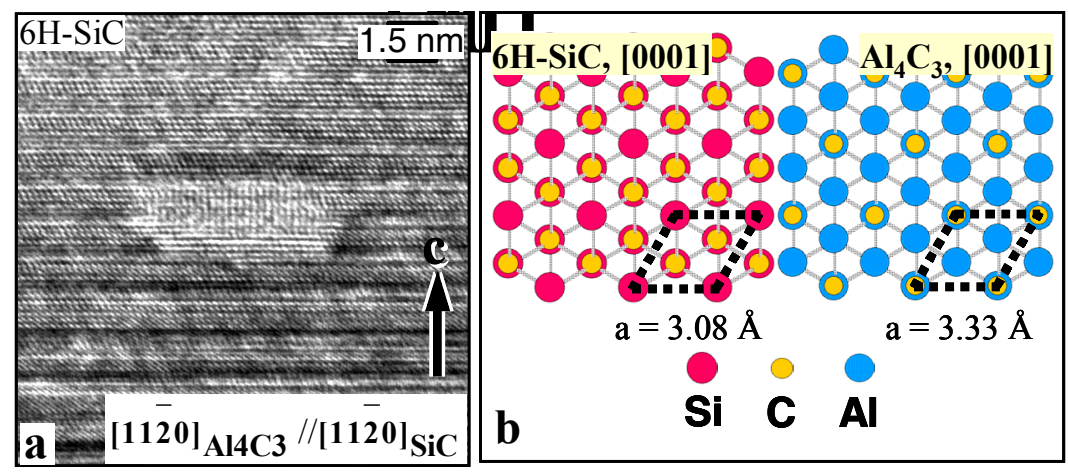

Figure 5: (a) $\mathrm{Al}_{4} \mathrm{C}_{3}$-based nanoprecipitate formed in a $6 \mathrm{H}-\mathrm{SiC}$ grain annealed at $1400^{\circ} \mathrm{C}$. The viewing directions are marked. (b) Atomic models for $6 \mathrm{H}-\mathrm{SiC}$ and $\mathrm{Al}_{4} \mathrm{C}_{3}$ projected along the [0001] direction. The similarity between the two structures can be seen.

The $\mathrm{Al}$ content in intergranular films as a function of annealing temperature was analyzed with EDS. The results are plotted in Figure 6. It is apparent that $\mathrm{Al}$ solution in $\mathrm{SiC}$ grains decreased at $1100^{\circ} \mathrm{C}$ and especially above $1300^{\circ} \mathrm{C}$, consistent with TEM observations that $\mathrm{Al}$ solutions formed nanoprecipitates exsolved from the $\mathrm{SiC}$ lattice. Not surprisingly, the $\mathrm{Al}$ site density in the grain boundaries $\left(\mathrm{N}_{\mathrm{Al}}^{\mathrm{GB}}\right)$ changed as well upon annealing. Below $1200^{\circ} \mathrm{C}$, the composition of intergranular films was virtually invariant, even while the intergranular films crystallized. The $\mathrm{N}_{\mathrm{Al}}{ }^{\mathrm{GB}}$ value was doubled at $1300^{\circ} \mathrm{C}$, which can be readily correlated with diffusion of the Al-rich chemical species into the grain boundary films. The Al content in intergranular films after annealing at $1300^{\circ} \mathrm{C}$ is in agreement with $\mathrm{Al}_{1.1} \mathrm{Si}_{0.9} \mathrm{OC}$, a solid solution between $2 \mathrm{H}$-wurtzite $\mathrm{Al}_{2} \mathrm{OC}$ and $\mathrm{SiC}$ [19]. At even higher annealing temperatures up to $1600^{\circ} \mathrm{C}, \mathrm{N}_{\mathrm{Al}}{ }^{\mathrm{GB}}$ changed marginally taking the standard deviation into account. 


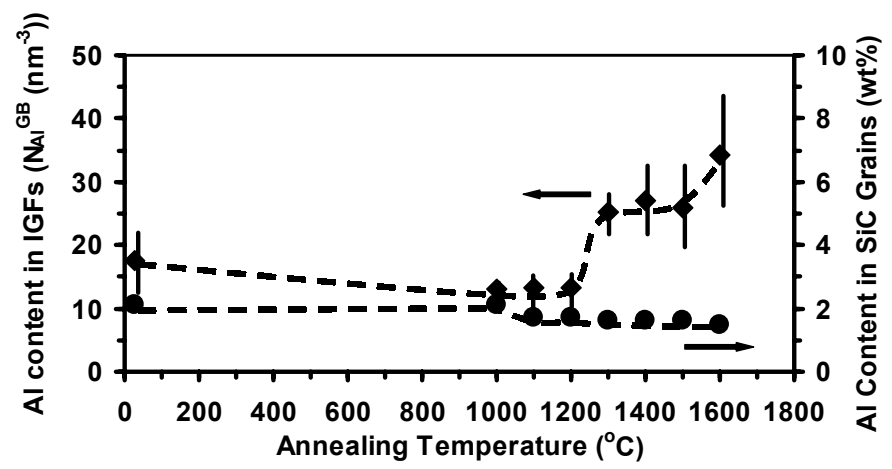

Figure 6: Plots of EDS-determined $\mathrm{Al}$ site density in grain boundary films $\left(\mathrm{N}_{\mathrm{Al}}{ }^{\mathrm{GB}}\right)$ and in $\mathrm{SiC}$ matrix grains $(\mathrm{Al} / \mathrm{SiC}, \mathrm{wt} \%)$ as a function of annealing temperature.

The structural evolutions in intergranular films during thermal treatment demonstrated a profound influence on mechanical properties. It was found that the high strength, cyclic fatigue resistance, and particularly the fracture toughness of $\mathrm{ABC}-\mathrm{SiC}$ at ambient temperature were not severely compromised at elevated temperatures. For example, the fatigue-crack growth properties up to $1300^{\circ} \mathrm{C}$ were essentially identical to those at $25^{\circ} \mathrm{C}$. Figure 7 illustrates the variation in fatigue-crack growth rates, $d a / d N$, with applied stress-intensity range, $\Delta K$, at a load ratio (minimum to maximum load) of $R=0.1$ for $\mathrm{ABC}-\mathrm{SiC}$ under different test conditions. It can be seen that at both $25^{\circ} \mathrm{C}$ and $1300^{\circ} \mathrm{C}$, crack-growth rates display a marked sensitivity to the stress intensity but little effect is from change of loading frequency over the range 3 to $1000 \mathrm{~Hz}$ [21-23]. Mechanistically, the lack of a frequency effect in $\mathrm{ABC}-\mathrm{SiC}$ is expected as crack advance occurs via predominantly intergranular cracking ahead of the tip, as shown in Figure 8. Grain bridging in the crack wake is a common feature. However, the absence of a frequency effect at elevated temperatures is surprising, particularly since comparable materials, such as $\mathrm{Si}_{3} \mathrm{~N}_{4}, \mathrm{Al}_{2} \mathrm{O}_{3}$ and silicide-matrix ceramics, show a marked sensitivity to frequency at above $1000^{\circ} \mathrm{C}$ [24-28]. In these later materials, softening of the intergranular films, grain boundary cavitation and viscous-phase bridging are common. In contrast, TEM studies of regions in the immediate vicinity of the crack tip in ABC-SiC (e.g. Figure 8) provided direct confirmation of fracture mechanisms which were similar at ambient and elevated temperatures, with no evidence for grain boundary cavitation (creep) damage or viscous-phase bridging at temperatures as high as $1300^{\circ} \mathrm{C}$. We conclude that the unique high-temperature mechanical characteristics of $\mathrm{ABC}$ $\mathrm{SiC}$ appear to be a result of the thermal-induced crystallization of intergranular glassy films. 


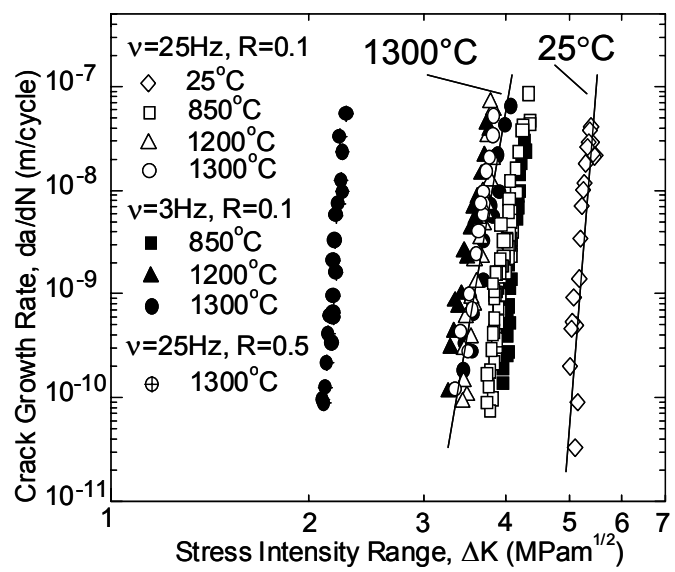

Figure 7: Cyclic fatigue-crack growth rates, $d a / d N$, in $\mathrm{ABC}-\mathrm{SiC}$ as a function of the applied stress-intensity range, $\Delta K$, for the tests conducted at temperatures between 25 and $1300^{\circ} \mathrm{C}$, load ratio $R=0.1$, and frequencies between 3 and $1000 \mathrm{~Hz}$.
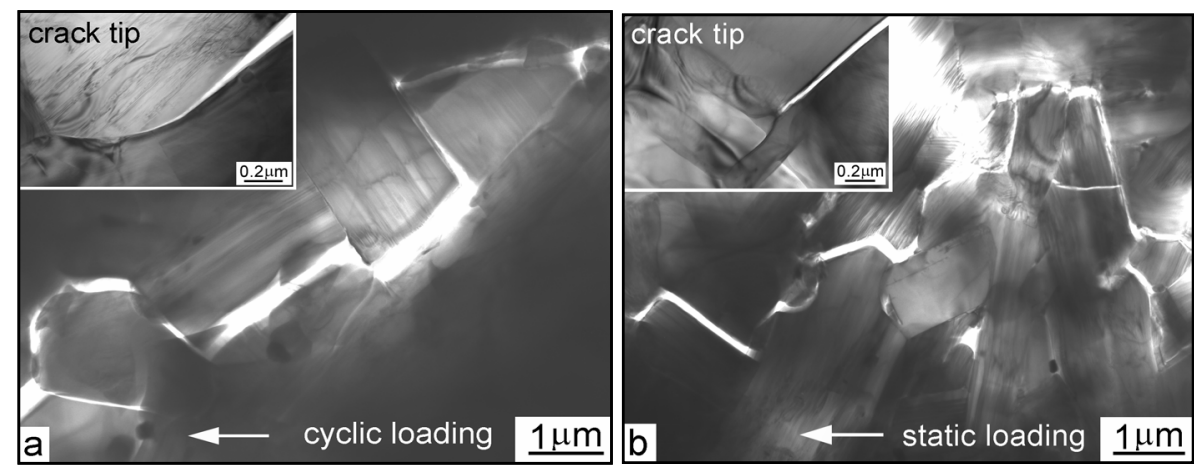

Figure 8: TEM images of the intergranular crack profiles at the crack tip region in $\mathrm{ABC}-\mathrm{SiC}$ at $1300^{\circ} \mathrm{C}$ under (a) cyclic loading $(25 \mathrm{~Hz}, R=0.1)$, and (b) static loading. Arrows indicate the general direction of crack propagation. No evidence of viscous grain boundary layers or creep damage.

The structural evolutions in grain boundary and matrix grains at elevated temperatures also benefit other mechanical properties of $\mathrm{ABC}-\mathrm{SiC}$. For example, the steady-state creep rate at high temperature of $1500^{\circ} \mathrm{C}$ was still impressively low $\left(5 \times 10^{-9} / \mathrm{s}\right.$ at $\left.100 \mathrm{MPa}\right)$, and the creep rates at $1200^{\circ} \mathrm{C}$ in $\mathrm{ABC}-\mathrm{SiC}$ was about three orders of magnitude slower than in single-crystal Ni-base superalloy tested under the same conditions [29]. In addition, $80 \%$ strength loss at $1300^{\circ} \mathrm{C}$ was restored by post-annealing [20]. Abrasive wear resistance was improved as well by formation of nanoprecipitates and by structural and compositional changes in grain boundaries after annealing [30]. These structural and mechanical characterization results demonstrate that the prescribed annealing is an effective way in tuning the microstructure and in turn optimizing the mechanical properties of $\mathrm{ABC}-\mathrm{SiC}$. 


\section{Effects of Additive Content}

Parallel to the post-annealing, another effort in tailoring microstructure and mechanical properties of $\mathrm{ABC}-\mathrm{SiC}$ was in adjusting the nominal contents of the $\mathrm{Al}, \mathrm{B}$, and $\mathrm{C}$ sintering additives. A series of samples were prepared by changing content of one of the three additives. For example, the $\mathrm{Al}$ content was $3 \mathrm{wt} \%$ in most ABC-SiC samples. This was then increased to 4 up to $7 \mathrm{wt} \%$, while boron and carbon contents remained at 0.6 and $2 \mathrm{wt} \%$, respectively. The samples were referred to as $3 \mathrm{ABC}-, 4 \mathrm{ABC}$, up to $7 \mathrm{ABC}-\mathrm{SiC}$, according to the weight percentage of the Al content. Structural characterizations showed that $\mathrm{Al}$ variations between 3 and $7 \mathrm{wt} \%$ did not reduce the densification of $\mathrm{SiC}$ samples under the same processing conditions. However, changing the $\mathrm{Al}$ content did alter the microstructure, as illustrated in Figure 9 (only images for the $3 \mathrm{ABC}-5 \mathrm{ABC}-$, and $7 \mathrm{ABC}-\mathrm{SiC}$ are shown). Although all samples were composed of platelike, elongated $\mathrm{SiC}$ grains and equiaxed $\mathrm{SiC}$ grains, the size, aspect ratio and area density of the elongated grains varied significantly with increasing $\mathrm{Al}$ content. The length of the elongated grains was found to be at a maximum in the $5 \mathrm{ABC}-\mathrm{SiC}$, with the aspect ratio increasing almost linearly up to $6 \mathrm{wt} \% \mathrm{Al}$. Compared to $3 \mathrm{ABC}-\mathrm{SiC}$, the aspect ratios in the $4 \mathrm{ABC}$ - to the $7 \mathrm{ABC}$ $\mathrm{SiC}$ are much higher, but the area density of these elongated grains continuously decreases. A distinct bimodal grain distribution is seen in the $5 \mathrm{ABC}-\mathrm{SiC}$, with elongated $\alpha-\mathrm{SiC}$ grains and submicron-sized equiaxed $\beta$-SiC grains [31].

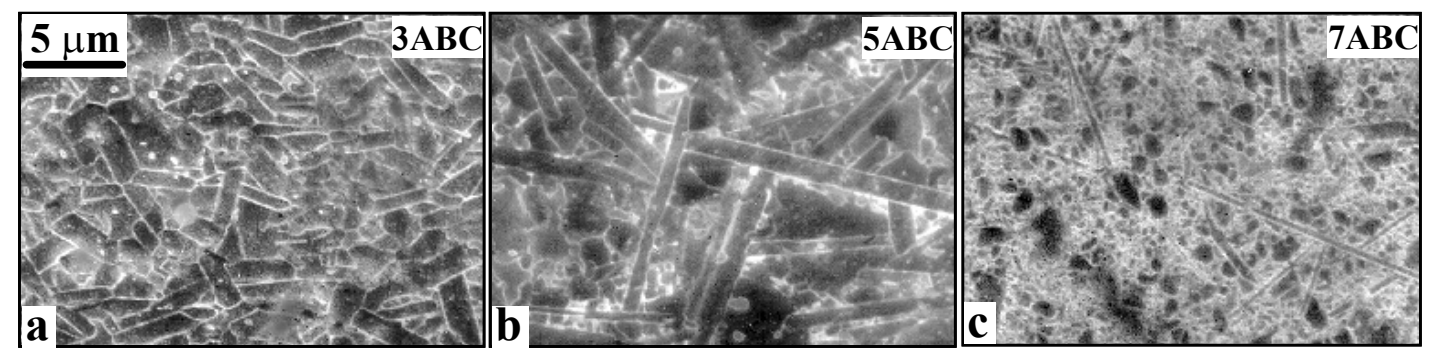

Figure 9: Morphologies of the $3 \mathrm{ABC}-, 5 \mathrm{ABC}-$, and $7 \mathrm{ABC}-\mathrm{SiC}$ are shown in images in (a) to (c), respectively. Note the significant changes in dimension and area density of the elongated $\mathrm{SiC}$ grains. Note also the bimodal grain systems with 5ABC-SiC.

Changing of the Al content by $1 \mathrm{wt} \%$ not only caused a considerable change in the grain morphology, but also induced different degrees of 3C-to-4H and/or $6 \mathrm{H}$-to-4H SiC phase conversion during hot-pressing. X-ray diffraction spectra were collected from polished surfaces of the 3ABC- to 7ABC-SiC samples and from the starting powder for comparison. The spectra were matched with standard 3C-, 4H-, 6H-, and 15R-SiC phase spectra; results are summarized in Table 2. It was found that the $3 \mathrm{wt} \% \mathrm{Al}$ addition in the $3 \mathrm{ABC}-\mathrm{SiC}$ was sufficient to transform all of the $20 \%$ preexisting $6 \mathrm{H}$-phase seeds in $3 \mathrm{C}$-dominanted starting powder into $4 \mathrm{H}$-SiC, with more than $50 \%$ of the $\beta-3 \mathrm{C}$ transforming into $\alpha-4 \mathrm{H}$ phase as well. However, a $1 \mathrm{wt} \%$ higher $\mathrm{Al}$ content resulted in a completely different phase composition by retarding the $3 \mathrm{C}$-to- $4 \mathrm{H}$ transformation. Further increases in Al monotonically decreased the extent of the $3 \mathrm{C}-$ to- $4 \mathrm{H}$ transformation, and apparently inhibited the preexisting $6 \mathrm{H}$ phase to be transformed into $4 \mathrm{H}$. These results imply that the $3 \mathrm{C}$-to- $4 \mathrm{H}$ transformation was mainly promoted by boron and carbon, and the transformation was retarded when boron and carbon were compensated by increasing the Al content. The experimental data also suggest close relationships between the phase 
composition and grain morphology, which would be expected if the $\beta$-to- $\alpha$ transformation promotes the grain elongation [10].

TABLE 2

X-RAY DIFFRACTION-DETERMINED POLYTIPIC SiC PHASES AND CORRESPONDING VOLUME FRACTIONS IN THE 3ABC- THROUGH THE 7ABC-SiC. MECHANICAL PROPERTIES ARE ALSO ListeD.

\begin{tabular}{|c|c|c|c|c|}
\hline Samples & $\begin{array}{c}\text { Phase and } \\
\text { Volume Fraction }\end{array}$ & $\begin{array}{l}\text { 4-Point Bending } \\
\text { Strength (MPa) }\end{array}$ & $\begin{array}{l}\text { Toughness } \\
\left(\mathrm{MPa}^{1 / 2}\right)^{1 / 2}\end{array}$ & $\begin{array}{c}\text { Hardness* } \\
(\text { GPa })\end{array}$ \\
\hline 3ABC-SiC & $\begin{array}{l}70 \% 4 \mathrm{H} \\
30 \% 3 \mathrm{C}\end{array}$ & $691 \pm 12$ & $6.8 \pm 0.3$ & 24.1 \\
\hline 4ABC-SiC & $\begin{array}{c}19 \% 6 \mathrm{H}, 23 \% 4 \mathrm{H} \\
58 \% 3 \mathrm{C}\end{array}$ & $561 \pm 13$ & $6.3 \pm 0.7$ & 23.9 \\
\hline 5ABC-SiC & $\begin{array}{c}21 \% 6 \mathrm{H}, 11 \% 4 \mathrm{H} \\
67 \% 3 \mathrm{C}\end{array}$ & $480 \pm 30$ & $8.9 \pm 0.4$ & 22.7 \\
\hline 6ABC-SiC & $\begin{array}{l}24 \% 6 \mathrm{H} \\
76 \% 3 \mathrm{C}\end{array}$ & $598 \pm 34$ & $3.2 \pm 0.2$ & 35.9 \\
\hline 7ABC-SiC & $\begin{array}{l}20 \% 6 \mathrm{H} \\
80 \% 3 \mathrm{C}\end{array}$ & $533 \pm 58$ & $3.9 \pm 0.4$ & 30.1 \\
\hline
\end{tabular}

$*$ Vickers indentation, Load $=10 \mathrm{~kg} . \quad E=430 \mathrm{GPa}$ (for calculation).

In addition to the grain morphology, a factor that may have a determining influence on mechanical properties of dense, polycrystalline ceramic materials is the grain boundary structure and composition, as noted above. High-resolution TEM showed that about $90 \%$ of the intergranular films examined in the $3 \mathrm{ABC}-\mathrm{SiC}$ processed an amorphous structure. In contrast, this fraction dropped to about $50 \%$ in the $5 \mathrm{ABC}-\mathrm{SiC}$, and all grain boundary films examined in the 7ABC-SiC were crystalline in structure. Quantitative EDS analyses indicated that increasing the nominal $\mathrm{Al}$ content enhanced $\mathrm{Al}$ concentration in the intergranular films, as well as in the $\mathrm{SiC}$ grains bulk, but the concentrations saturated in $5 \mathrm{ABC}-\mathrm{SiC}$. More than $5 \mathrm{wt} \% \mathrm{Al}$ resulted in precipitation of excessive free $\mathrm{Al}$, as observed in the 6ABC-and 7ABC-SiC. It should be pointed out that crystalline grain boundaries were prevalent in as-hot-pressed $5 \mathrm{ABC}$-, to $7 \mathrm{ABC}-\mathrm{SiC}$ without any post-treatment. It is thus plausible that enhanced $\mathrm{Al}$ facilitates formation of crystalline intergranular films.

These changes in microstructure can be expected to affect mechanical properties. Table 2 lists various mechanical properties for the sample series. The mechanical data illustrate the tradeoff mechanical performance which is often encountered in developing advanced ceramic materials. While the highest strength was obtained in the 3ABC-SiC, the hardness was at maximum for the 6ABC-SiC. As for toughness, it is clear that $5 \mathrm{wt} \% \mathrm{Al}$ resulted in the best toughness whereas 6 $\mathrm{wt} \%$ or higher $\mathrm{Al}$ additions significantly degraded the toughness so that the materials became extremely brittle. Cyclic fatigue tests revealed that the $3 \mathrm{ABC}$ - and particularly the 5ABC-SiC displayed excellent crack-growth resistance at both ambient $\left(25^{\circ} \mathrm{C}\right)$ and elevated $\left(1300^{\circ} \mathrm{C}\right)$ temperatures. Again, the crack propagation in both $3 \mathrm{ABC}$ - and $5 \mathrm{ABC}-\mathrm{SiC}$ was intergranular, and crack bridging was observed in the crack wake. No evidence of viscous grain boundary layers and creep damage, in the form of grain-boundary cavitation, was seen at temperatures up 
to $1300^{\circ} \mathrm{C}$. The substantially enhanced toughness in the $5 \mathrm{ABC}-\mathrm{SiC}$ was associated with extensive crack bridging from both interlocking grains, as in $3 \mathrm{ABC}-\mathrm{SiC}$, and uncracked ligaments, which only occurred in $5 \mathrm{ABC}-\mathrm{SiC}$. No toughening by crack bridging was apparent in 7ABC-SiC, concomitant with a transition from intergranular to transgranular fracture [32].

Similar to the aluminum concentration variations, changes in boron and carbon contents also alter the microstructure and phase composition. Typical results are shown in Figure 10. In this case, the $\mathrm{Al}$ content was fixed at $6 \mathrm{wt} \%$, while either the $\mathrm{B}$ or the $\mathrm{C}$ concentrations were changed. The phase composition determined by X-ray diffraction is noted in each image. It is clear that at fixed $\mathrm{Al}(6 \mathrm{wt} \%)$ and $\mathrm{B}(0.6 \mathrm{wt} \%)$ contents, $1 \mathrm{wt} \%$ additional carbon promoted the formation of more elongated grains and enhanced the $3 \mathrm{C}$-to- $4 \mathrm{H}$ transformation (most of the $6 \mathrm{H}$ phase should originate from starting powder). This effect of carbon on 3C-to-4H transformation was also reported before by Sakai et al [33]. Growth of the equiaxed grains was found to be limited. With the $\mathrm{Al}$ and $\mathrm{C}$ contents kept constant, increasing the boron content from $0.6 \mathrm{wt} \%$ to $0.9 \mathrm{wt} \%$ largely increased the number density of elongated grains, but reduced their aspect ratio. In addition, boron promoted the $3 \mathrm{C}-$ to $-4 \mathrm{H}$ and $6 \mathrm{H}-$ to- $4 \mathrm{H}$ phase transformations more effectively than carbon. The positive effect of boron on the $6 \mathrm{H}-$ to- $4 \mathrm{H}$ transformation is consistent with the previous observations of Huang et al [34].

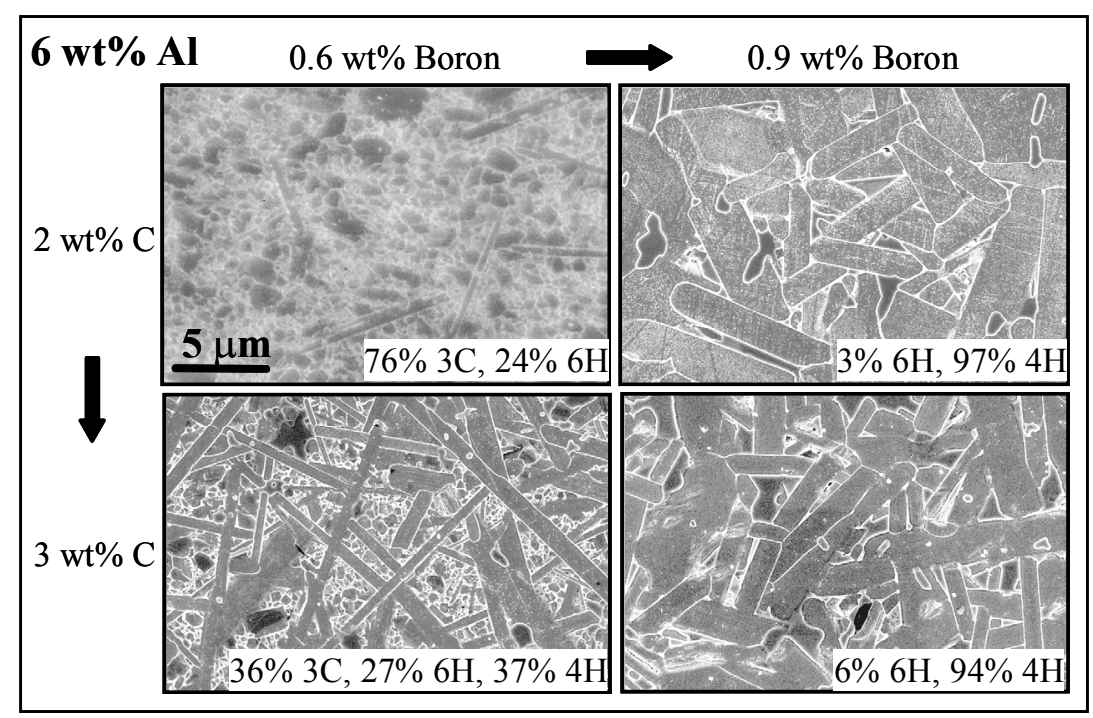

Figure 10: Microstructural changes with fixed $\mathrm{Al}(6 \mathrm{wt} \%)$ and adjusted boron or carbon contents. Phase compositions are marked in each image. Effects of boron and carbon additions in changing microstructure and phase composition are clear.

The systematic processing and characterizations of a series of $\mathrm{ABC}-\mathrm{SiC}$ described above also allowed for the determination of the roles of $\mathrm{Al}, \mathrm{B}$, and $\mathrm{C}$ additives in developing the microstructures of silicon carbide. The observed effects may be summarized as follows: in terms of developing phase composition, boron is more effective in promoting the $\beta$-to- $\alpha$ phase transformations than carbon. Aluminum retards the $\beta$-to- $\alpha$ phase transformation, but promotes the $6 \mathrm{H}$-to- $4 \mathrm{H}$ transformation. As for the developing grain morphology, aluminum and carbon both promote anisotropic grain growth, whereas boron tends to coarsen the volume fraction, but reduce the aspect ratio, of the elongated grains. It should be noted that during processing, the 
combined roles of the $\mathrm{Al}, \mathrm{B}$ and $\mathrm{C}$ additives often override their individual roles. For example, $\mathrm{B}$ and $\mathrm{C}$ together favor of the $\beta$-to- $\alpha$ phase transformation associated with grain elongation; however, the final microstructure does not necessarily have strongly elongated grains as $\mathrm{B}$ and $\mathrm{C}$ have opposite effects on anisotropic grain growth. Actually, the B:C ratio determines the final grain configuration. Aluminum has a different effect: when the $\mathrm{B}: \mathrm{C}$ ratio favors the anisotropic grain growth, Al-rich liquid phase accelerates such growth so that the aspect ratio is further increased. However, if the $\mathrm{Al}: \mathrm{B}$ and $\mathrm{Al}: \mathrm{C}$ ratios are reduced, less liquid phases are expected to be present after the Al-B-C reactions so that the effects of $\mathrm{Al}$ are diminished. Further experiments have indicated that even at constant $\mathrm{Al}: \mathrm{B}: \mathrm{C}$ ratios, a change in total amount of additives can still alter the grain configuration and phase composition significantly. This emphasizes the fact that the optimization of the mechanical properties of many structural ceramics such as $\mathrm{ABC}-\mathrm{SiC}$ is a strong function of the absolute and relative amounts of the sintering additives.

\section{SUMMARY}

ABC-SiC ceramics with unprecedented toughness values as high as $9 \mathrm{MPa} \cdot \mathrm{m}^{1 / 2}$ have been developed by hot pressing $\beta$-SiC powder with additions of $\mathrm{Al}, \mathrm{B}$ and $\mathrm{C}$. Such high fracture toughnesses were attributed to an in situ toughening mechanism primarily involving crack bridging by interlocked and elongated $\mathrm{SiC}$ grains. The anisotropic growth of $\mathrm{SiC}$ grains, which promoted such toughening, was the result of the liquid-phase sintering in which $\mathrm{Al}$ additives acted to form a liquid phase. The existence of this liquid phase also lowered the sintering temperature to $1900^{\circ} \mathrm{C}$. The toughening mechanism also requires intergranular cracking which was aided by the presence of amorphous intergranular films (typically $1 \mathrm{~nm}$ in width) in the grain boundaries of the as-processed ABC-SiC. Two effective methods for modifying the grain boundary structure and chemistry, as well as the overall microstructure, were investigated using post-processing annealing and adjustments in the nominal contents of sintering additives.

Prescribed post-annealing treatments at higher than $1000^{\circ} \mathrm{C}$ were found to activate grain boundary diffusion and consequently caused the crystallization of most of the glassy intergranular films (not simply the "pockets" at the grain boundary triple points). This led to superior high temperature strength, creep and fatigue properties at elevated temperatures with no evidence of creep damage in the form of grain boundary cavitation until temperatures above $1400^{\circ} \mathrm{C}$ were reached. Using atomic-resolution electron microscopy and quantitative nanoprobe EDS, one of the crystallized intergranular structures was identified as $2 \mathrm{H}$-wurtzite aluminosilicate. Heating at $1300^{\circ} \mathrm{C}$ or higher also resulted in uniformly dispersed nanoprecipitates as a result of lattice diffusion. In addition, the lattice diffusion almost doubled the segregation of Al into the intergranular films. It is believed that this significant microstructural evolution, which occurs during post-annealing and is not characteristically observed in other advanced ceramics such as $\mathrm{Si}_{3} \mathrm{~N}_{4}$, and $\mathrm{Al}_{2} \mathrm{O}_{3}$, is the origin of the many outstanding mechanical property attributes of $\mathrm{ABC}-\mathrm{SiC}$ at elevated temperatures. These include high resistance to crack growth at temperatures between ambient and $1300^{\circ} \mathrm{C}$, far superior steady-state creep resistance than in single-crystal Ni-base superalloys, enhanced resistance to abrasive wear, and high-temperature strength loss recovery. 
Changing the nominal contents of the sintering additives, $\mathrm{Al}$, or $\mathrm{B}$, or $\mathrm{C}$, was also used as an effective means to modify the microstructure. In particular, the area density and dimensions of the elongated $\mathrm{SiC}$ grains, their phase composition, and the grain boundary structure were all found to be sensitive to small variations in additive content. Using this approach, a series of materials processing with systematic changes in sintering atom additions were used to develop optimal microstructures for ABC-SiC. Compositions with superior fracture toughness, or creep properties or abrasive wear resistance were all defined. Such methods, in conjunction with prescribed post-annealing heat treatments, permit the tailoring of microstructures in $\mathrm{ABC}-\mathrm{SiC}$ to achieve and optimize a wide range of mechanical properties in a highly controlled manner.

\section{ACKNOWLEDGMENTS}

This work was supported by the Director, Office of Science, Office of Basic Energy Sciences, Division of Materials Sciences and Engineering of the U.S. Department of Energy under Contract No. DE-AC03-76SF0098. Part of this work was made possible through the use of the National Center for Electron Microscopy facility at the Lawrence Berkeley National Laboratory. Thanks are due to Da Chen, Mark E. Sixta, Qing Yang, Rong Yuan, Jay J. Kruzic, and Rowland Cannon for their assistance and discussion in this work.

\section{REFERENCES}

1. Faber, K.T. and Evans, A.G. (1983) Acta Metall. 31, 565.

2. $\quad$ Faber, K.T. and Evans, A.G. (1983) Acta Metall. 31, 577.

3. Becher, P.F. (1991) J. Am. Ceram. Soc., 74, 255.

4. Becher, P.F., Sun, E.Y., Plucknett, K.P., Alexander, K.B., Husueh, C.-H., Lin, H.-T., Waters, S.B. and Westmoreland, C.G. (1998) J. Am. Ceram. Soc. 81, 2821.

5. Cao, J.J., MoberlyChan, W.J., De Jonghe, L.C., Gilbert, C.J. and. Ritchie, R.O. (1996) J. Am. Ceram. Soc. 79, 461.

6. $\quad$ Thomas, G. (1994) Ultramicroscopy 54, 145.

7. Thomas, G. (1996) J. Euro. Ceram. Soc. 16, 323.

8. Zhang, X.F., Sixta, M.E. and De Jonghe, L.C. (2000) J. Am. Ceram. Soc. 83, 2813.

9. Zhang, X.F., Yang, Q., De Jonghe, L.C. and Zhang, Z. (2002) J. Microsc. 207, 58.

10. MoberlyChan, W.J., Cao, J.J., Gilbert, C.J., Ritchie, R.O. and De Jonghe, L.C. (1998), In: Ceramic Microstructure: Control at the Atomic Level, pp. 177-190, Tomsia A.P. and Glaeser A. (Eds). New York: Plenum Press.

11. Gilbert, C.J., Cao, J.J., De Jonghe, L.C. and Ritchie, R.O. (1997) J. Am. Ceram. Soc. 80, 2253.

12. Kleebe, H.-J., Cinibulk, M.K., Cannon, R.M. and Rühle, M. (1993) J. Am. Ceram. Soc. 76, 1969.

13. Chiang, Y.-M., Silverman, L.A., French, R.H. and Cannon, R.M. (1994) J. Am. Ceram. Soc., 77, 1143.

14. Clarke, D.R. (1987) J. Am. Ceram. Soc. 70, 15.

15. Hamminger, R., Grathwohl, G. and Thummler, F. (1983) J. Mater. Sci. 18, 3154.

16. Lane, J. E., Carter, C.H. and Davis, R. F. (1988) J. Am. Ceram. Soc., 71, 281. 
17. Zhang, X.F., Sixta, M.E. and De Jonghe, L.C. (2001) J. Am. Ceram. Soc. 84, 813.

18. Goto, Y. and Thomas, G. (1995) J. Mater. Sci. 30, 2194.

19. Cutler, I.B., Miller, P.D., Rafaniello, W., Park, H.K., Thompson, D.P. and Jack, K.H. (1978) Nature 275, 434.

20. Zhang, X.F., Sixta, M.E. and De Jonghe, L.C. (2001) J. Mater. Sci. 36, 5447.

21. Chen, D., Gilbert, C.J., Zhang, X.F. and Ritchie, R.O. (2000) Acta Mater, 48, 659.

22. Chen, D., Zhang, X.F. and Ritchie, R.O. (2000) J. Am. Ceram. Soc. 83, 2079.

23. Chen, D., Sixta, M.E., Zhang, X.F., De Jonghe, L.C. and Ritchie, R.O. (2000) Acta Mater. 48, 4599.

24. Hansson, T., Miyashita, Y. and Mutoh, Y. (1996), In: Fracture Mechanics of Ceramics, Vol. 12, pp. 187-201, Bradt R.C. (Ed). Plenum Press, New York.

25. Zhang, Y.H. and Edwards, L. (1998) Mater. Sci. Eng. A256, 144.

26. Edwards, L. and Suresh, S. (1992) J. Mater. Sci. 27, 5181.

27. Liu S.Y., Chen, I.W. and Tien, T.Y. (1994) J. Am. Ceram. Soc. 77, 137.

28. Ramamurty, U., Kim, A.S., Suresh, S. (1993) J. Am. Ceram. Soc. 76, 1953.

29. Sixta, M.E., Zhang, X.F. and De Jonghe, L.C. (2001) J. Am. Ceram. Soc. 84, 2022.

30. Zhang, X.F., Lee, G.Y., Chen, D., Ritchie, R.O. and De Jonghe, L.C. (2003) J. Am. Ceram. Soc., in press.

31. Zhang, X.F., Yang, Q. and De Jonghe, L.C. (2003) Acta Mater., in press.

32. Yuan, R., Kruzic, J. J., Zhang, X. F., De Jonghe, L. C. and Ritchie, R. O. (2003) J. Am. Ceram. Soc., submitted.

33. Sakai, T. and Aikawa, T. (1988) J. Am. Ceram. Soc. 71, C-7.

34. Huang, J.-L., Hurford, A.C., Cutler, R.A. and Virkar, A.V. (1986) J. Mater. Sci. Lett. 21, 1448. 